\title{
A low transition temperature mixture for the dispersive liquid-liquid microextraction of pesticides from surface waters
}

\author{
Pierpaolo Tomai ${ }^{a}$, Anna Lippiello ${ }^{a}$, Paola D’Angelo ${ }^{a}$, Ingmar Persson $^{b}$, Andrea Martinelli $^{\mathrm{a}}$ \\ , Valerio Di Lisio ${ }^{a}$, Roberta Curini ${ }^{\mathrm{a}}$, Chiara Fanali ${ }^{\mathrm{c}}$, Alessandra Gentilia ${ }^{\mathrm{a}, *}$ \\ a Department of Chemistry “Sapienza" University” of Rome, P.le Aldo Moro 5, 00185, Rome, Italy \\ ${ }^{\mathrm{b}}$ Department of Chemistry, Swedish University of Agricultural Sciences, P.O. Box 7015, 75007 Uppsala, Sweden \\ c Unit of Food Science and Nutrition, Department of Medicine, Università Campus Bio-Medico di Roma, Via Alvaro del Portillo 21, 00128, Rome, Italy
}

\section{A R T I C L E I N F O}

\section{Article history:}

Received 3 May 2019

Received in revised form 22 June 2019

Accepted 24 June 2019

Available online $\mathrm{xxx}$

\section{Keywords:}

Low transition temperature mixture

Deep eutectic solvents

Dispersive liquid-liquid microextraction

Sample preparation

Environmental samples

LC-MS

\begin{abstract}
A B S T R A C T
This paper illustrates the development of a procedure based on the use of a low transition temperature mixture (LTTM) for the dispersive liquid-liquid microextraction (DLLME) of fungicides, insecticides and acaricides from surface waters. The LTTM preparation involves the heat-mixing of choline chloride and acetylsalicylic acid in a molar ratio $1: 2\left(\mathrm{ChCl}(\mathrm{ASA})_{2}\right)$. The resulting mixture appears as a clear viscous liquid at room-temperature, denser than water $\left(1.20 \pm 0.01 \mathrm{~g} \mathrm{~mL}^{-1}\right)$. For its characterization, differential scanning calorimetry (DSC) provided crucial evidence to classify it as a LTTM rather than as a deep eutectic solvent (DES) since it revealed an intense glass transition at $-37^{\circ} \mathrm{C}$. Large-angle X-ray scattering (LAXS) confirmed the lack of any long-distance order. Due to the LTTM immiscibility with water, an evaluation study was carried out to test $\mathrm{ChCl}(\mathrm{ASA})_{2}$ as an effective alternative to the conventional chlorinated solvents for DLLME. To this end, 24 pesticides were used as model compounds, extracted from surface water samples $(5 \mathrm{~mL})$ and analyzed by high-performance liquid chromatography-tandem mass spectrometry (HPLC-MS/MS). The definitive procedure required the optimization of some key parameters such as volume of extracting solvent, type and volume of dispersing solvent, volume of the aqueous sample, LTTM dispersion procedure, and extraction time. Depending on $\mathrm{pKa}$ and $\operatorname{logP}$ values, recoveries ranged from 18 (for very polar compounds) to $96 \%$, revealing that the ideal candidates for the extraction with $\mathrm{ChCl}(\mathrm{ASA})_{2}$ are neutral compounds with $\log \mathrm{P}>2$. After complete validation, the method was applied to analyze water samples from the River Tiber where dodine and dimetomorph were found at low $\mu \mathrm{g} \mathrm{L}^{-1}$ concentration levels.
\end{abstract}

(c) 2019 Elsevier B.V. All rights reserved.

\section{Introduction}

Deep eutectic solvents (DESs) [1] and low transition temperature mixtures (LTTMs) [2] are neoteric solvents [3] which have recently aroused the keen interest of the scientific community for displaying the same physical properties of ionic liquids (ILs), with which they are closely related. Their singular capacity of solubilizing some inorganic and organic compounds, refractory to the conventional molecular solvents, has made their use especially captivating for applications in electrochemistry, catalysis and separation processes $[2,4]$.

The term DES was conceived by Abbot and his co-workers in 2003 [5] to describe any mixture with a marked ("deep") drop of

\footnotetext{
* Corresponding author.

E-mail address: alessandra.gentili@uniroma1.it (A. Gentili).
}

the melting point in comparison with the values of the individual solid components. Actually, some of such mixtures were already known in the $50 \mathrm{~s}$ of the twentieth century [6-8]. Nowadays, DESs are systematically described by the general formula $\mathrm{Cat}^{+} \mathrm{X}^{-} z \mathrm{Y}[2]$, where $\mathrm{Cat}^{+} \mathrm{X}^{-}$is a salt, often composed by a quaternary ammonium cation and a Lewis base as counterion (e.g. $\mathrm{Cl}^{-}$); $\mathrm{Y}$ is a Lewis or Brønsted acid which acts as complexing agent and $z$ is the number of Y molecules. Depending on the nature of Y, DESs have been classified in four main classes [2]: in all cases, Y tends to complex with $\mathrm{X}^{-}$to give $\mathrm{Cat}^{+}[\mathrm{XY}]^{-}$; however, the complexation of $\mathrm{Y}$ with $\mathrm{Cat}^{+}$to give $[\mathrm{CatY}]^{+} \mathrm{X}^{-}$is also possible [9]. Among such classes, the real novelty is represented by the so-called type-III DESs [2] because they are the result of a self-association mediated by $\mathrm{H}$ bonds mainly between $\mathrm{X}^{-}$and $\mathrm{Y}$, where $\mathrm{X}^{-}$and $\mathrm{Y}$ act as an acceptor (HBA) and a donor (HBD) of H-bond, respectively. So far, the most frequently studied DESs have been those resulting from the mixing of $\mathrm{ChCl}$ with an amide or alcohol (e.g. urea or glycerol) in exact 
molar ratios, usually $1: 1,1: 2$ or $1: 3$. For such mixtures, the decrease in the melting point has been ascribed to the strength of the anionic $\mathrm{H}$-bond (e.g. $\mathrm{Cl}^{-} \ldots \mathrm{HBD}$ ) $[2,10]$, responsible for charge delocalization occurring on $\mathrm{Cl}^{-}$and consequent weakening of the $\mathrm{Ch}^{+} \mathrm{Cl}^{-}$ electrostatic interaction. In general, it has been observed that the stronger the H-bond, the deeper the depression of freezing point. In particular, it has been hypothesized that a crucial role would be played by the pKa values of HBD and HBA $[3,11]$. In fact, since Hbond results from both electrostatic and covalent contributions, its strength increases with the covalent component, namely as the difference of donor-acceptor acidic constants approaches zero $\left(\Delta \mathrm{p} K_{\mathrm{a}} \sim 0\right)[11,12]$.

At the present moment, the research into DESs is still in its infancy and several studies are in progress to unravel mechanisms of both eutectic formation and action as solvent systems. For the same reasons, much work is still to be done to adequately characterize DESs and LTTMs and avoid using the two terms indiscriminately [13]. LTTMs are similar to DESs, but instead of having a melting/freezing point, they display a glass transition [3]. Like DESs, LTTMs are obtainable with a high degree of purity, simply mixing the two solid components under moderate heating. Method of preparation, cost-effectiveness of starting products ( $\mathrm{ChCl}$ and many HBDs are available around $2-4 € \mathrm{Kg}^{-1}$ ) and real recyclability (the mixture can be disrupted by dilution leading to the recrystallization of both or one of the initial compounds) make these solvents appropriate to meet the circular economy requirements.

The use of neoteric solvents is an attractive alternative to the classical molecular solvents or the unique solution to dissolve poorly soluble solutes. So far, $\mathrm{ChCl}(\text { urea })_{2}$ and $\mathrm{ChCl}(\text { phenol })_{3}$ have been the main DESs used for such purposes [14]. Nevertheless, considering the very high number of theoretical combinations (around $10^{6}$ ), a variety of DESs and LTTMs can be designed with physicochemical properties advantageously tailored. And what is more, such properties, including polarity, viscosity and aptitude to dissolve materials of special interest, can further be modulated by varying the ratio between the selected HBA and HBD. Compared to ILs, the stoichiometry flexibility is an additional advantage.

The applications of neoteric solvents within the framework of sample preparation are still limited [14-24] and new procedures are necessary because there is a significant limitation in the literature regarding different groups of compounds in samples of different nature. Most of these applications involve liquidphase microextraction (LPM) techniques [15-24]. Among them, dispersive liquid-liquid microextraction (DLLME) stands out for its simplicity, inexpensiveness, rapidity, high enrichment factor (EF), and great extraction efficiency. Assadi et al. came up with it in 2006 [25] with the major aim of significantly reducing the organic solvent consumption, but the use of chlorinated solvents remains the only downside.

To the best of our knowledge, no paper describing the explicit use of LTTMs as extraction systems for DLLME-based applications has been published so far. The aim of this work is to illustrate the advantages in using the mixture prepared and characterized for the first time in our lab. This LTTM, which appears as a transparent viscous liquid at room temperature, is obtained by heat-mixing $\mathrm{ChCl}$ and acetylsalicylic acid (ASA) in a molar ratio 1:2. The two starting solid materials are low price available, biocompatible and potentially recoverable by breaking the LTTM H-bond networks. The mixture composition was designed to avoid the well-known drawbacks of chlorinated solvents. Characterization by means of differential scanning calorimetry (DSC) and large-angle X-ray scattering (LAXS) allowed us to classify $\mathrm{ChCl}(\mathrm{ASA})_{2}$ as an LTTM. The novel mixture was experimented as an extractant for an environmental DLLME-based application. Its extraction efficiency was assessed by recovering 24 pesticides, belonging to several chemical classes and known to be common environmental pollutants, from surface water samples.

\section{Experimental}

\subsection{Chemicals, materials and solutions}

Authentic standards of acetamiprid, azoxystrobin, boscalid, buprofezin, chlorpyrifos, chlorpyrifos-methyl, clofentezine, dimetomorph, dodine, fluquinconazole, fludioxonil, hexythiazox, imidacloprid, methyl-thiophanate, methoxyfenozide, myclobutanil, penconazole, propiconazole, pyraclostrobin, pyriproxyfen, pyridaben, spirotetramat, tebuconazole, and tebufenpyrad were acquired from Aldrich-Fluka-Sigma S.r.l. (Milan, Italy). All standards were more than $98 \%$ pure. Table S1 in the Supporting Information lists all 24 pesticides with the physicochemical characteristics of interest for this study.

Acetonitrile (AcCN), methanol (MeOH), ethanol (EtOH), dimethyl sulfoxide (DMSO), toluene and tetrahydrofuran (THF), $\mathrm{ChCl}$, ASA, phenol $(\mathrm{Ph})$ were obtained from Sigma-Aldrich S.r.l. Ultrapure water was produced from a Milli-Q water generator (Millipore, Bedford, MA, USA).

Individual stock solutions were prepared by dissolving weighed standard amounts in $\mathrm{MeOH}$ (most analytes) or toluene (clofentezine, dimetomorph, fluquinconazole and pyraclostrobin) at a concentration of $1 \mathrm{mg} \mathrm{mL}^{-1}$. Only solutions of propiconazole and dimetomorph were at $0.5 \mathrm{mg} \mathrm{mL}^{-1}$, while that of fluquinconazole at $10 \mathrm{mg} \mathrm{mL}^{-1}$. Working composite standard solutions were obtained by diluting a mix of the individual ones with $\mathrm{MeOH}$ at concentrations depending on the purpose. All standards and solutions were kept at $4^{\circ} \mathrm{C}$ in the darkness when unused.

\subsection{Environmental samples}

Surface water samples were gathered in 5-L dark glass bottles from Lake Martignano and from four different sites along the River Tiber (Fig. S1): Oasi di Farfa (a natural area, $50 \mathrm{~km}$ north of Rome); Tor di Quinto (northern suburb of Rome); Tiber Island in the center of Rome; Marconi Bridge (southern suburb of Rome). Before the extraction, all samples were filtered through $1.2 \mu \mathrm{m}$ Whatman glass microfiber filters (Whatman International Ltd, Maidstone, UK) and held at $4{ }^{\circ} \mathrm{C}$. Preliminary analyses showed that samples from Lake Martignano could be used as blanks to perform the method optimization and validation.

\subsection{Preparation of $\mathrm{ChCl}(\mathrm{ASA})_{2}$ mixture}

Preliminarily to the preparation of $\mathrm{ChCl}(\mathrm{ASA})_{2}, \mathrm{ChCl}$ and ASA were dried in a muffle oven at $90^{\circ} \mathrm{C}$ for $24 \mathrm{~h}$. Once completed the drying process, $1.107 \mathrm{~g}$ of $\mathrm{ChCl}$ and $2.858 \mathrm{~g}$ of ASA were quickly weighed in a $25-\mathrm{mL}$ weighing bottle and blended with a spatula. Then, the weighing bottle was closed and heated on a heating plate at a temperature of about $80^{\circ} \mathrm{C}$ for $1 \mathrm{~h}$. These conditions avoided triggering decomposition processes (see subsection 2.6 Thermogravimetric analysis). The mixture $(\sim 3 \mathrm{~mL})$ was then allowed to cool at room temperature, appearing as a transparent viscous liquid. Once cooled to room temperature, $\mathrm{MeOH}(578 \mu \mathrm{L})$ was added and mixed quickly with a spatula to reduce viscosity and favor the LTTM sampling with a micro-syringe (the molar ratio $\mathrm{ChCl}(\mathrm{ASA})_{2}: \mathrm{MeOH}$ was $1: 1.8)$. The overall mixture, referred to as $\mathrm{ChCl}(\mathrm{ASA})_{2} \mathrm{MeOH}$, had a total volume of $3.5 \mathrm{~mL}$, suitable for at least 35 extractions.

\subsection{Extraction procedure}

The different steps of the extraction procedure are schematically shown in Fig. 1. A centrifuge tube $(15 \mathrm{~mL}$ falcon) was filled 


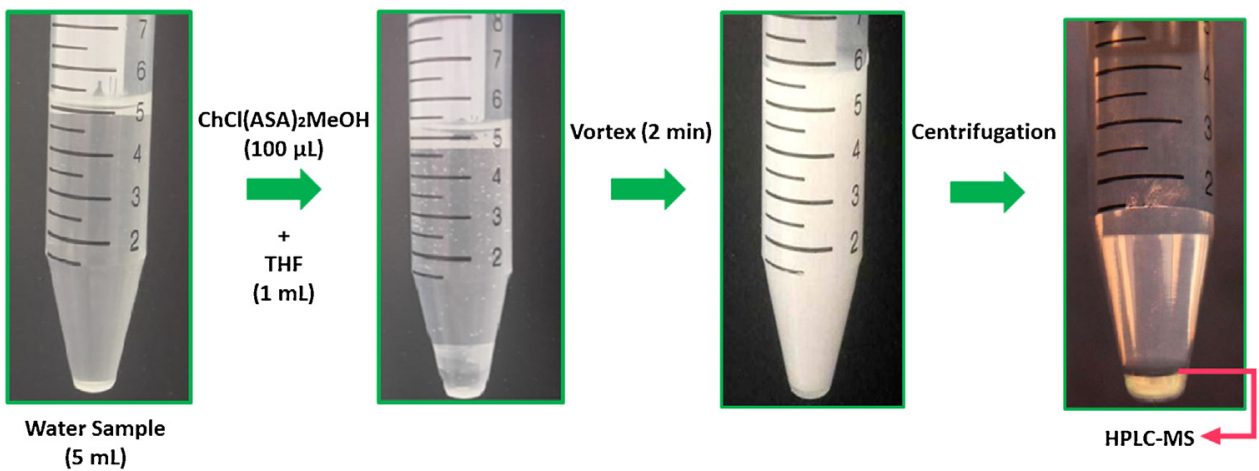

Fig. 1. Schematic illustration of the DLLME procedure using $\mathrm{ChCl}(\mathrm{ASA})_{2} \mathrm{MeOH}$ as extractant.

with $5 \mathrm{~mL}$ of surface water. $100 \mu \mathrm{L}$ of $\mathrm{ChCl}(\mathrm{ASA})_{2} \mathrm{MeOH}$ (extraction solvent) and $1 \mathrm{~mL}$ of THF (dispersing solvent) were taken with Hamilton syringes and sequentially injected into the aqueous sample. After stirring on a vortex mixer for $2 \mathrm{~min}$, the aqueous solution appeared cloudy due to the fine dispersion achieved. The mixture was then centrifuged at $12,500 \mathrm{~g}$ for $10 \mathrm{~min}$ at room temperature. After centrifugation, a phase separation was observed. The $\mathrm{ChCl}(\mathrm{ASA})_{2}$ mixture, being denser, settled on the bottom of the tube and was taken with a micro-syringe $(70 \mu \mathrm{L}$ volume of final extract). After dilution with $30 \mu \mathrm{L}$ of $\mathrm{MeOH}(100 \mu \mathrm{L}$ of total final volume), $10 \mu \mathrm{L}$ were injected for the HPLC-MS analysis.

\subsection{High-performance liquid chromatography-tandem mass spectrometry}

The HPLC apparatus was a Perkin Elmer series 200 binary pump equipped with an autosampler (Perkin Elmer, Norwalk, CT). The analytes were chromatographed on a XTerra $C_{18}(5 \mu \mathrm{m})$ column $(4.6 \times 250 \mathrm{~mm})$, protected by a guard column (Waters, Milford, Massachusetts, USA). Water (phase A) and AcCN (phase B), both $5 \mathrm{mM}$ in formic acid, were used as mobile phases. At a flow rate of $1 \mathrm{~mL}$ $\mathrm{min}^{-1}$, a gradient elution was carried out increasing the percentage of B from $35 \%$ to $100 \%$ in 16 min and, then, keeping B at $100 \%$ for $4 \mathrm{~min}$. A post-column T-valve split the mobile phase, leading $200 \mu \mathrm{L} \mathrm{min}^{-1}$ into the ESI source of the mass spectrometer. After each injection, the autosampler needle was washed with AcCN.

The triple quadrupole mass spectrometer was a PE-Sciex API$3000^{\circledR}$ (Perkin Elmer Sciex Toronto, Canada), equipped with an ESI source operated in positive ionization. The capillary voltage was $+4500 \mathrm{~V}$. High purity nitrogen was used as curtain and collision gas, while air as nebulizer and drying gas. The last one was heated by setting the source heather temperature at $350^{\circ} \mathrm{C}$. The full width at half maximum (FWHM) was set at $m / z 0.7 \pm 0.1$ in each mass-resolving quadrupole to operate with a unit resolution. The scheduled multiple reaction monitoring (SMRM) mode was used for the analyte quantification, setting an MRM detection window of $120 \mathrm{~s}$ in the retention window characteristic of each analyte $\left(t_{r} \pm 60 \mathrm{~s}\right)$ and a target scan time of $2 \mathrm{~s}$. Two SMRM transitions were selected per analyte, for a total of 48 ion currents monitored with a pause time of $5 \mathrm{~ms}$. All the LC-MS parameters, useful for identification and quantification, are listed in Table S2. The LC-MS data were processed by Analyst $^{\circledR} 1.5$ Software (AB Sciex). Fig. 2 shows the LC-MRM chromatogram of a surface water sample spiked pre-extraction with the analytes at their LOQ level.

\subsection{Thermogravimetric analysis (TGA)}

The thermal stability of $\mathrm{ChCl}(\mathrm{ASA})_{2}, \mathrm{ChCl}$ and ASA were investigated by thermogravimetric analysis (TGA) carried out by using a Mettler Toledo TG50 measuring module linked to a Mettler
Toledo TC 10 interface. About $10 \mathrm{mg}$ of dried sample ( $\mathrm{ChCl}$, ASA or $\mathrm{ChCl}(\mathrm{ASA})_{2}$ ) was weighted in a ceramic pan which, after being closed with a lid, was rapidly placed in the measuring furnace and purged with $30 \mathrm{~mL} \mathrm{~min}^{-1}$ nitrogen flux. TGA curves were acquired during the heating from $30^{\circ} \mathrm{C}$ to $500^{\circ} \mathrm{C}$ at $10^{\circ} \mathrm{C} \mathrm{min}^{-1}$.

\subsection{Differential scanning calorimetry (DSC)}

The thermal properties of $\mathrm{ChCl}(\mathrm{ASA})_{2}$ were characterized by DSC by using a Mettler Toledo DSC 822e instrument (Mettler Toledo, Greifensee, Switzerland). About $2 \mathrm{mg}$ of sample was rapidly weighed in an aluminum pan and sealed to avoid water absorption. The sample was cooled from 20 to $-150^{\circ} \mathrm{C}$ and, then, heated up to $20^{\circ} \mathrm{C}$, using a scanning rate of $10^{\circ} \mathrm{C} \mathrm{min}^{-1}$. The furnace was purged by dry nitrogen at a flow rate of $30 \mathrm{ml} \mathrm{min}^{-1}$.

\subsection{Large-angle X-ray scattering (LAXS)}

A large-angle $\theta-\theta$ diffractometer was employed to measure the scattering of MoKa radiation $(\lambda=0.7107)$ on the free surfaces of a liquid mixture of $\mathrm{ChCl}(\mathrm{ASA})_{2}\left(\rho=1.20 \mathrm{~g} \cdot \mathrm{cm}^{-3}\right.$, and $\left.\mu=2.022 \mathrm{~cm}^{-1}\right)$ and liquid mixture of $\mathrm{ChCl}(\mathrm{ASA})_{2}$ diluted with $\mathrm{MeOH}\left(\mathrm{ChCl}(\mathrm{ASA})_{2}\right.$ - MeOH 1:1.8 M ratio) $\left(\rho=1.23 \mathrm{~g} \cdot \mathrm{cm}^{-3}\right.$, and $\left.\mu=1.919 \mathrm{~cm}^{-1}\right)$. The solutions were contained in a Teflon cuvette with an air-tight radiation shielding with beryllium windows. The scattered radiation was monochromatized in a focusing LiF crystal monochromator and the intensity was measured at 450 discrete points in the range $1<\theta<65^{\circ}$ (the scattering angle is $2 \theta$ ). 100,000 counts were accumulated at each preset angle, and the whole angular range was scanned twice, which corresponds to a statistical error of about $0.3 \%$. The divergence of the primary X-ray beam was limited by 1 or $14^{\circ}$ slits for different $\theta$ regions with some parts of the data overlapping for scaling purposes. All of the data treatment was performed with the KURVLR program [26]. All the details in the data treatment approach can be found elsewhere [27]. The experimental intensities were normalized to a stoichiometric unit of volume containing one chlorine atom, using the scattering factors $f$ for neutral atoms, including corrections for anomalous dispersion $\Delta f$ and $\Delta f^{\prime}$ [28], and values for Compton scattering [29,30]. Least-squares refinements of the model parameters were carried out by means of the STEPLR program [31], where the expression $U=\Sigma\left[s \cdot i_{\exp }(s)\right.$ $\left.-s \cdot i_{\text {calc }}(s)\right]^{2}$ is minimized. In order to obtain a better alignment of the intensity function before the refinements, a Fourier backtransformation procedure was used to correct the $i_{\exp }(s)$ functions by removing spurious non-physical peaks below $1.2 \AA$ in the experimental radial distribution function (RDF) [32]. Corrections due to the low absorptions coefficients, $\mu$, have been applied [26]. 


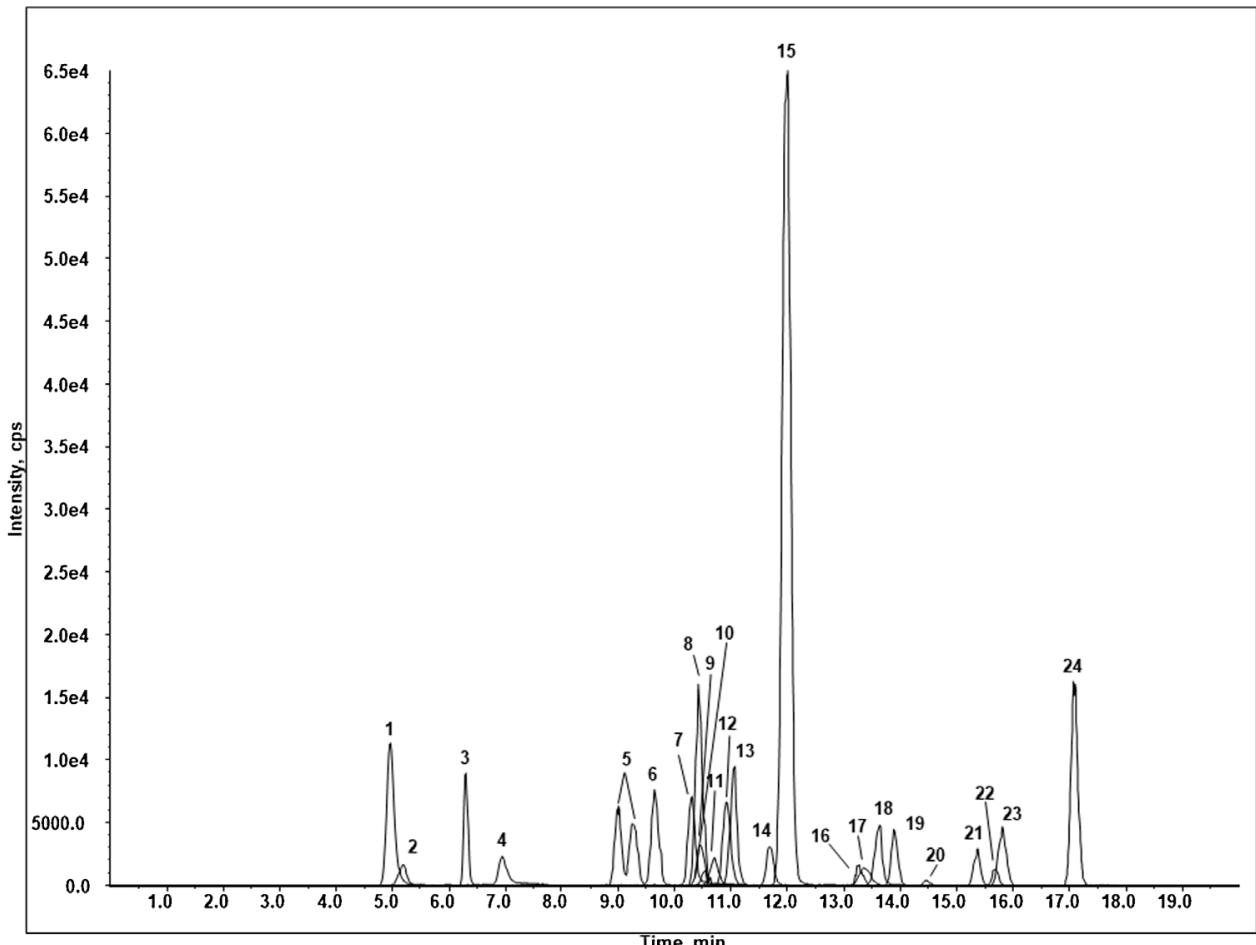

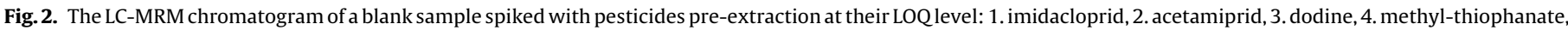

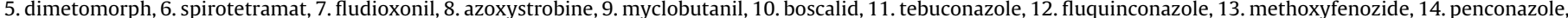

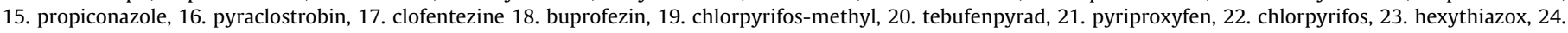
pyridaben.

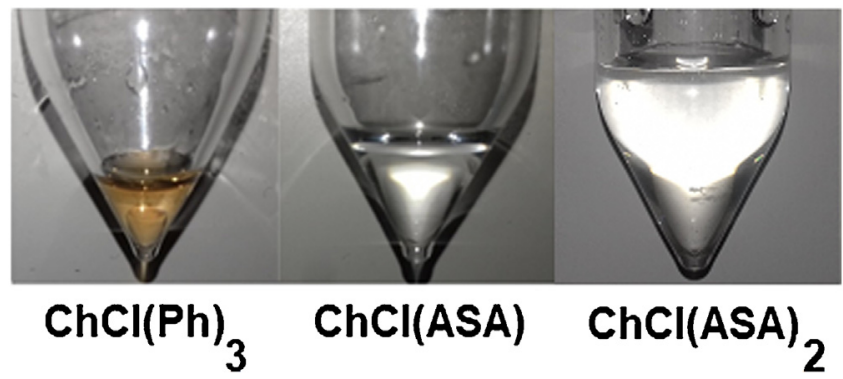

Fig. 3. Photograph of the LTTMs prepared for this study.

\section{Results and discussion}

\subsection{Preparation of some neoteric solvents}

A series of mixtures (see Table 1 and Fig. 3) were prepared to be evaluated as extractants in a DLLME-based application. The mixture $\mathrm{ChCl}(\mathrm{Ph})_{3}$, already known in the literature [14], turned into liquid directly at room temperature by stirring the starting solid components with a spatula for 3-5 minutes. Both mixtures of $\mathrm{ChCl}$ and salicylic acid (SA) solidified when cooled to room temperature; they probably give rise neither to DES nor to LTTM because SA prefers forming an intramolecular $\mathrm{H}$-bond (six-term ring) rather than acting as a $\mathrm{HBD}$ with $\mathrm{ChCl}$. The mixtures $\mathrm{ChCl}(\mathrm{ASA})$ and $\mathrm{ChCl}(\mathrm{ASA})_{2}$ were stable and liquid at room temperature. $\mathrm{ChCl}(\mathrm{ASA})$ was diluted with $\mathrm{MeOH}$, in the same proportion as $\mathrm{ChCl}(\mathrm{ASA})_{2}$, to reduce its viscosity. It must be mentioned that $\mathrm{ChCl}(\mathrm{ASA})$ was prepared for the first time by another research group as a liquid formulation of an API (active pharmaceutical ingredient) to enhance the bioavailability and rate of delivery of the drug [33].

\subsection{Selection of the extraction solvent}

The selection of the extraction solvent was decided by planning parallel tests to compare the extraction yields of $\mathrm{ChCl}(\mathrm{ASA})_{2} \mathrm{MeOH}$, $\mathrm{ChCl}(\mathrm{ASA}) \mathrm{MeOH}$ and $\mathrm{ChCl}(\mathrm{Ph})_{3}$. To this end, $100 \mu \mathrm{L}$ of extractant and $500 \mu \mathrm{L}$ of THF were quickly injected into an aqueous sample ( $5 \mathrm{~mL}$ of Milli-Q water spiked with pesticides at $2 \mu \mathrm{g} \mathrm{L}^{-1}$ ) and the dispersion was vortexed for $2 \mathrm{~min}$. However, after centrifugation, $\mathrm{ChCl}(\mathrm{ASA})_{2}$ and $\mathrm{ChCl}(\mathrm{ASA})$ settled at the bottom of the falcon tube, while $\mathrm{ChCl}(\mathrm{Ph})_{3}$ floated on the aqueous sample. Once taken with a micro-syringe, $10 \mu \mathrm{L}$ were directly injected into the HPLCMS apparatus (these mixtures cannot be evaporated to dryness). From the comparison of the average value of the areas of all analytes ( 3 replicates per type of neoteric solvent), $\mathrm{ChCl}(\mathrm{ASA})_{2}$ showed a general better performance (see Fig. S2); so, it was chosen also considering the lower toxicity of ASA as compared with that of $\mathrm{Ph}$ $\left(\mathrm{LD}_{50 \mathrm{ASA}}=1124 \mathrm{mg} \mathrm{Kg}^{-1} ; \mathrm{LD}_{50 \mathrm{Ph}}=660 \mathrm{mg} \mathrm{Kg}^{-1}\right)$.

\subsection{Characterization of the $\mathrm{ChCl}(\mathrm{ASA})_{2}$ mixture}

\subsubsection{Density measurement}

Due to its high viscosity, the mixture was heated up to $80^{\circ} \mathrm{C}$, taken with a pipette and quickly introduced into a 1 -mL flask. Then, it was allowed to cool to room temperature and the sample volume checked for possible contraction. $1 \mathrm{~mL}$ of $\mathrm{ChCl}(\mathrm{ASA})_{2}$ was weighed on a microbalance (OHAUS DV215CD Discovery Semi-Micro and Analytical Balance $81 \mathrm{~g} / 210 \mathrm{~g}$ capacity, $0.01 \mathrm{mg} / 0.1 \mathrm{mg}$ readability). Density was calculated as the mean of three replicates:

$\rho=\mathrm{m} / \mathrm{V}=1.20 \pm 0.01 \mathrm{gmL}^{-1}$

As it can be seen, density is greater than that of water, in accordance with values found for other DESs/LTTMs [34] and with our experimental observations, i.e. sedimentation of $\mathrm{ChCl}(\mathrm{ASA})_{2}$ after the centrifugation step of the DLLME procedure. 
Table 1

Conditions for the preparation of some DESs/LTTMs.

\begin{tabular}{|c|c|c|c|}
\hline \multicolumn{2}{|l|}{ Components } & \multirow{2}{*}{ Molar ratio } & \multirow{2}{*}{$\begin{array}{l}\text { Temperature of } \\
\text { preparation }\left({ }^{\circ} \mathrm{C}\right)\end{array}$} \\
\hline Hydrogen-Bond Acceptor (HBA) & Hydrogen-Bond Donor (HBD) $)^{b}$ & & \\
\hline Choline chloride & phenol & $1: 3$ & ambient \\
\hline Choline chloride & salycilic acid & $1: 1$ & $80^{\circ} \mathrm{C}$ \\
\hline Choline chloride & salycilic acid & $1: 2$ & $80^{\circ} \mathrm{C}$ \\
\hline Choline chloride & acetylsalycilic acidc & $1: 1$ & $80^{\circ} \mathrm{C}$ \\
\hline Choline chloride & acetylsalycilic acide & $1: 2$ & $80^{\circ} \mathrm{C}$ \\
\hline
\end{tabular}

a $\mathrm{T}_{\text {melting } \mathrm{HBA}}: 302^{\circ} \mathrm{C}$.

b $\mathrm{T}_{\text {melting } \mathrm{HBD}}: 41^{\circ} \mathrm{C}$ (phenol), $135^{\circ} \mathrm{C}$ (acetylsalycilic acid), $159^{\circ} \mathrm{C}$ (salycilic acid).

Table 2

Thermogravimetric analysis results of $\mathrm{ASA}, \mathrm{ChCl}$ and $\mathrm{ChCl}(\mathrm{ASA})_{2}$ samples.

\begin{tabular}{llll}
\hline Sample & $\mathrm{T}_{\mathrm{d}}{ }^{10 \%}\left({ }^{\circ} \mathrm{C}\right)$ & $\mathrm{T}_{\mathrm{p}}{ }^{1}\left({ }^{\circ} \mathrm{C}\right)$ & $\mathrm{T}_{\mathrm{p}}{ }^{\mathrm{II}}\left({ }^{\circ} \mathrm{C}\right)$ \\
\hline $\mathrm{ASA}$ & 177 & 200 & 390 \\
$\mathrm{ChCl}$ & 320 & 336 & - \\
$\mathrm{ChCl}(\mathrm{ASA})_{2}$ & 225 & 257 & 378 \\
\hline
\end{tabular}

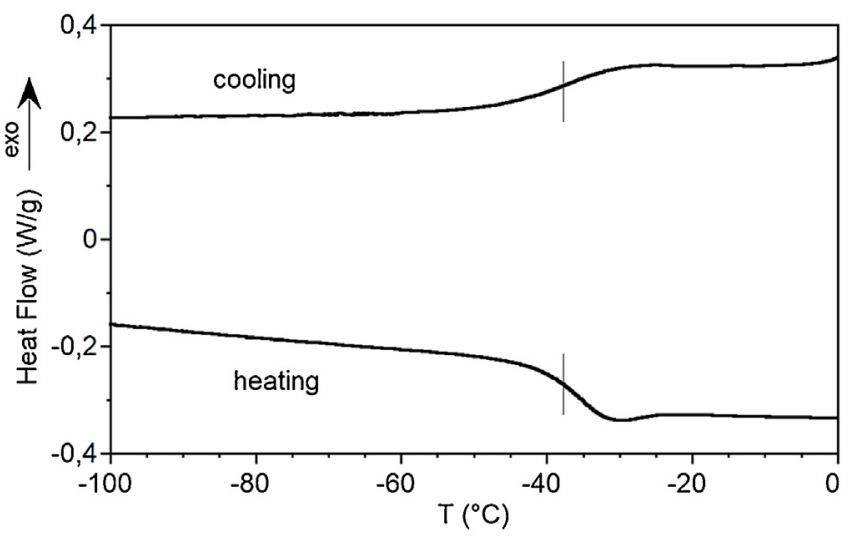

Fig. 4. Cooling and heating DSC profiles of $\mathrm{ChCl}(\mathrm{ASA})_{2}$ recorded at $10^{\circ} \mathrm{C} \mathrm{min}^{-1}$. The vertical lines indicate the glass transition temperature $\mathrm{T}_{\mathrm{g}}$ at midpoint.

\subsubsection{Thermogravimetric analysis}

TGA and differential TGA (DTGA) curves of $\mathrm{ChCl}$, ASA, and $\mathrm{ChCl}(\mathrm{ASA})_{2}$ are displayed in Fig. S3, while the temperatures in correspondence of a $10 \%$ weight loss $\left(\mathrm{T}_{\mathrm{d}}{ }^{10 \%}\right)$ and of the DTGA peaks $\left(\mathrm{T}_{\mathrm{p}}{ }^{\mathrm{I}}\right.$ and $\mathrm{T}_{\mathrm{p}}{ }^{\mathrm{II}}$ ) are reported in Table 2 .

As reported in literature [35,36], $\mathrm{ChCl}$ starts to decompose at about $320^{\circ} \mathrm{C}$, meanwhile ASA shows a two-step decomposition, the first beginning at about $180^{\circ} \mathrm{C}$ and the second at $350^{\circ} \mathrm{C}$.

The neoteric solvent has the main weight loss at an intermediate temperature $\left(257^{\circ} \mathrm{C}\right)$. At higher temperature, the second decomposition process occurs approximately at $\mathrm{T}_{\mathrm{p}}$ II of ASA and can be attributed to small amount of SA, possibly formed by deacetylation during the $\mathrm{ChCl}(\mathrm{ASA})_{2}$ heating scan or during the LTTM preparation [37].

\subsubsection{Differential scanning calorimetry (DSC)}

Fig. 4 shows the thermogram of $\mathrm{ChCl}(\mathrm{ASA})_{2}$ obtained in the cooling and heating scans. In both runs only an intense glass transition at $-37^{\circ} \mathrm{C}$ (midpoint) is observed (vertical bars in Fig. 4). The specific heat variation at the glass transition is about $6 \mathrm{~J} \mathrm{~g}^{-1} \mathrm{~K}^{-1}$. Under the employed experimental conditions, the sample does not undergo a phase transition, crystallization or melting, and, therefore, it can be defined as a LTTM.

\subsubsection{Large-angle $X$-ray scattering (LAXS)}

The radial distribution functions of the mixture of $\mathrm{ChCl}(\mathrm{ASA})_{2}$ and of the liquid mixture of $\mathrm{ChCl}(\mathrm{ASA})_{2}$ diluted with $\mathrm{MeOH}(1: 1.8 \mathrm{M}$ ratio) are very similar (see Fig. S4). The strong contribution at ca. $2.4 \AA$ can be modelled with 60 O-O distances, but they can be also ascribed to $\mathrm{C}-\mathrm{C}$ from stacked phenyl rings or other intermolecular distances as $\mathrm{N}-(\mathrm{H})-\mathrm{O}$. Besides the intramolecular distances within $\mathrm{Ch}, \mathrm{ASA}$ and $\mathrm{MeOH}$, and the $2.4 \AA \mathrm{A}$ distance, there is a broad peak at ca. $4.7 \AA$ which certainly contains several different intermolecular distances that have not been included in the model as their contribution to the LAXS function can be neglected above $\theta=4 \AA^{-1}$. Outside $7.5 \AA$ there seems not to be any preferred distances at all, in strong contradiction to e.g. water and DMSO [38].

\subsection{Optimization of the DLLME extraction}

The volume of the extracting solvent, type and volume of dispersing solvent, dispersing device (vortex and ultrasound) and time of dispersion were the parameters investigated to study the behavior of $\mathrm{ChCl}(\mathrm{ASA})_{2}$ in aqueous solution and to maximize the extraction of the 24 pesticides. Such experiments were carried out in triplicates using $5 \mathrm{~mL}$ of Milli-Q water samples spiked with analytes at $2 \mu \mathrm{g} \mathrm{L}^{-1}$.

\subsubsection{Optimization of the extraction solvent volume}

As far as the extractant volume choice is concerned $(50,100$, $200,300 \mu \mathrm{L}$ of $\left.\mathrm{ChCl}(\mathrm{ASA})_{2} \mathrm{MeOH}\right)$, the chromatographic analysis showed that the peaks areas decreased as the volume of the extractant increased (Fig. S5A), obviously due to the lower achieved EF ( $\mathrm{V}_{\text {water }} / \mathrm{V}_{\text {settled }}$ ). However, using $50 \mu \mathrm{L}$ of the mixture, the settled phase was difficult to recover. Therefore, $100 \mu \mathrm{L}$ was considered the optimal compromise between $\mathrm{EF}$ and recoverable volume of the settled phase.

\subsubsection{Selection of the dispersing solvents}

The dispersing solvent must: $i$ ) be miscible with both water and extraction solvent; $i$ i) assist the extractant dispersion; iii) facilitate the analyte extraction from the aqueous to the organic phase. In case of equal performance, the selection of the dispersing solvent should be based on toxicity and cost.

In this study, THF, DMSO, EtOH, AcCN and $\mathrm{MeOH}$ were tested as dispersing solvents because of their miscibility in water and ability to solubilize ASA (THF $>$ DMSO $>$ EtOH $>$ AcCN $>\mathrm{MeOH}$ ). To make a decision, 15 samples were spiked with the analytes and extracted, using $100 \mu \mathrm{L}$ of $\mathrm{ChCl}(\mathrm{ASA})_{2} \mathrm{MeOH}$ and $500 \mu \mathrm{L}$ of each dispersing solvent. Results showed that the LTTM dispersion was effectively supported by THF, DMSO and EtOH. Although DMSO and EtOH have lower toxicity, THF was chosen for its greater efficiency in assisting both the extractant dispersion and analyte extraction. Probably, the capability of THF in dissolving ASA may explain its higher efficacy compared to that of the other dispersing solvents.

Another critical parameter is the volume of dispersing solvent. Its impact on extraction yields was evaluated testing $0.1,0.3,0.5$, 1.0 , and $1.5 \mathrm{~mL}$ of THF. The use of a low volume $(0.1 \mathrm{~mL})$ made it problematic the formation of a stable dispersion. On the other hand, volumes higher than $0.5 \mathrm{~mL}$ led to a progressive volume increase of 
Table 3

Regression parameters, LODs and LOQs for the selected pesticides.

\begin{tabular}{|c|c|c|c|c|c|}
\hline \multirow{3}{*}{ Standard } & \multicolumn{2}{|c|}{ Matrix-matched calibration curve } & \multirow{3}{*}{$\mathrm{R}^{2}$} & \multirow{3}{*}{$\begin{array}{l}\text { LODs } \\
\mu \mathrm{g} \mathrm{L}^{-1}\end{array}$} & \multirow[t]{3}{*}{ LOQs } \\
\hline & \multirow{2}{*}{$\begin{array}{l}\mathrm{m} \pm \mathrm{S}_{\mathrm{m}} \cdot \mathrm{t}_{(0.05 ; 5)} \\
\operatorname{cps} \mu \mathrm{g}^{-1} \mathrm{~L}\end{array}$} & \multirow{2}{*}{$\begin{array}{l}\mathrm{q} \pm \mathrm{S}_{\mathrm{q}} \cdot \mathrm{t}_{(0.05 ; 5)} \\
\mathrm{cps}^{\mathrm{a}}\end{array}$} & & & \\
\hline & & & & & \\
\hline Imidacloprid & $21 \pm 2$ & $21 \pm 1$ & 0.9905 & 0.04 & 0.1 \\
\hline Acetamiprid & $87 \pm 4$ & $61.9 \pm 0.2$ & 0.9961 & 0.01 & 0.04 \\
\hline Dodine & $68 \pm 4$ & $57.8 \pm 0.2$ & 0.9890 & 0.02 & 0.08 \\
\hline Methyl-thiophanate & $133 \pm 1$ & $-0.96 \pm 0.08$ & 0.9975 & 0.005 & 0.02 \\
\hline Dimetomorph & $67 \pm 3$ & $-91 \pm 2$ & 0.9737 & 0.003 & 0.009 \\
\hline Spirotetramat & $263 \pm 2$ & $203 \pm 1$ & 0.9900 & 0.009 & 0.03 \\
\hline Fludioxonil & $0.7 \pm 0.1$ & $0.6 \pm 0.1$ & 0.9911 & 2.3 & 7.7 \\
\hline Azoxystrobin & $337 \pm 11$ & $494 \pm 1$ & 0.9863 & 0.002 & 0.006 \\
\hline Myclobutanil & $90 \pm 13$ & $83.4 \pm 0.5$ & 0.9910 & 0.003 & 0.01 \\
\hline Boscalid & $40 \pm 1$ & $67.9 \pm 0.3$ & 0.9861 & 0.01 & 0.05 \\
\hline Tebuconazole & $166 \pm 9$ & $240 \pm 1$ & 0.9897 & 0.003 & 0.009 \\
\hline Fluquinconazole & $77 \pm 6$ & $123 \pm 2$ & 0.9896 & 0.01 & 0.05 \\
\hline Methoxyfenozide & $258 \pm 5$ & $228 \pm 3$ & 0.9967 & 0.01 & 0.04 \\
\hline Penconazole & $76 \pm 7$ & $105.7 \pm 0.2$ & 0.9924 & 0.008 & 0.03 \\
\hline Propiconazole & $97 \pm 4$ & $116.9 \pm 0.1$ & 0.9947 & 0.02 & 0.07 \\
\hline Pyraclostrobin & $37 \pm 3$ & $8.86 \pm 0.02$ & 0.9808 & 0.01 & 0.04 \\
\hline Clofentezine & $16 \pm 1$ & $14.9 \pm 0.1$ & 0.9759 & 0.08 & 0.3 \\
\hline Buprofezin & $277 \pm 9$ & $105 \pm 1$ & 0.9973 & 0.004 & 0.01 \\
\hline Chlorpyrifos-methyl & $2.9 \pm 0.1$ & $1.15 \pm 0.03$ & 0.9849 & 0.3 & 0.9 \\
\hline Tebufenpyrad & $35 \pm 1$ & $29.2 \pm 0.01$ & 0.9833 & 0.02 & 0.06 \\
\hline Pyriproxyfen & $301 \pm 11$ & $455 \pm 1$ & 0.9812 & 0.003 & 0.01 \\
\hline Chlorpyrifos & $2.9 \pm 0.1$ & $4.45 \pm 0.01$ & 0.9772 & 0.2 & 0.7 \\
\hline Hexythiazox & $19 \pm 1$ & $-5.92 \pm 0.01$ & 0.9853 & 0.03 & 0.1 \\
\hline Pyridaben & $17 \pm 2$ & $-1 \pm 1$ & 0.9975 & 0.04 & 0.1 \\
\hline
\end{tabular}

a cps (count per second) is the arbitrary unit used for the MS signal.

Table 4

Recovery (\%) and precision (\%) for the selected pesticides.

\begin{tabular}{|c|c|c|c|c|}
\hline \multirow{3}{*}{ Standard } & \multirow{2}{*}{\multicolumn{2}{|c|}{$\begin{array}{l}\text { Recovery (intra-day precision) } \\
\text { Spike levels }\end{array}$}} & \multirow{2}{*}{\multicolumn{2}{|c|}{$\begin{array}{l}\text { Interday precision } \\
\text { Spike levels }\end{array}$}} \\
\hline & & & & \\
\hline & LOQ & 10 LOQ & LOQ & 10 LOQ \\
\hline Imidacloprid & $22(6)$ & $21(12)$ & 12 & 14 \\
\hline Acetamiprid & $29(13)$ & $18(10)$ & 9 & 12 \\
\hline Dodine & $80(7)$ & $81(7)$ & 9 & 9 \\
\hline Methyl-thiophanate & $61(8)$ & $70(15)$ & 13 & 15 \\
\hline Dimetomorph & $83(10)$ & $85(7)$ & 10 & 9 \\
\hline Spirotetramat & $80(14)$ & $79(8)$ & 14 & 10 \\
\hline Fludioxonil & $91(12)$ & $83(9)$ & 12 & 12 \\
\hline Azoxystrobin & $88(10)$ & $80(6)$ & 14 & 13 \\
\hline Myclobutanil & $71(13)$ & $76(3)$ & 14 & 5 \\
\hline Boscalid & $88(6)$ & $91(10)$ & 6 & 12 \\
\hline Tebuconazole & $90(14)$ & $89(7)$ & 11 & 9 \\
\hline Fluquinconazole & $46(12)$ & $44(7)$ & 12 & 10 \\
\hline Methoxyfenozide & $83(12)$ & $77(7)$ & 12 & 8 \\
\hline Penconazole & $79(13)$ & $81(8)$ & 14 & 9 \\
\hline Propiconazole & $77(7)$ & $89(6)$ & 10 & 8 \\
\hline Pyraclostrobin & $68(13)$ & $56(7)$ & 13 & 7 \\
\hline Clofentezine & $66(9)$ & $96(5)$ & 10 & 7 \\
\hline Buprofezin & $81(9)$ & $94(10)$ & 10 & 11 \\
\hline Chlorpyrifos-methyl & $92(11)$ & $85(13)$ & 14 & 13 \\
\hline Tebufenpyrad & $49(3)$ & $88(4)$ & 5 & 6 \\
\hline Pyriproxyfen & $87(11)$ & $74(9)$ & 12 & 10 \\
\hline Chlorpyrifos & $91(12)$ & $73(10)$ & 12 & 12 \\
\hline Hexythiazox & $92(9)$ & $81(13)$ & 10 & 14 \\
\hline Pyridaben & $90(11)$ & $71(8)$ & 12 & 10 \\
\hline
\end{tabular}

the settled phase (up to $90 \mu \mathrm{L}$ ) and, at the same time, to a decrease of EF. For this reason, the best compromise was achieved using just $1 \mathrm{~mL}$ of THF ( $70 \mu \mathrm{L}$ of settled phase). The effect of the dispersing solvent on the average area of the chromatographic peaks is shown in Fig. S5B.

\subsubsection{Dispersion medium and extraction time}

The other parameters to be evaluate were the device to support the dispersion (vortex and ultrasound) and the extraction time (1, 2 and $4 \mathrm{~min}$ ). Comparing the mean value of the chromatographic peaks areas, the best extraction was obtained by vortexing for 2 min (Fig. S5C).

\subsubsection{Real sample volume}

The following step was to evaluate the optimal sample volume to increase EF and sensitivity. To this end, two different volumes ( $5 \mathrm{~mL}$ and $10 \mathrm{~mL}$ ) of an unspiked sample of natural water (from the River Tiber at Tor di Quinto) were analyzed in triplicates. When a 10-mL volume was processed, no distinct advantage was obtained both applying the optimized conditions ( $1 \mathrm{~mL}$ of THF and $100 \mu \mathrm{L}$ 
Table 5

Levels of some pesticides $\left(\mu \mathrm{g} \mathrm{L}^{-1}\right.$ ) found in the four sampling sites along the River Tiber basin (Central Italy)

\begin{tabular}{|c|c|c|c|c|}
\hline Analytes & $\begin{array}{l}\text { Oasis of Farfa } \\
\left(\mu \mathrm{g} \mathrm{L}^{-1}\right)\end{array}$ & Tor di Quinto & Tiber Island & Marconi \\
\hline Dodine & $<$ LOQ & $2.04 \pm 0.06$ & $0.36 \pm 0.01$ & $<$ LOQ \\
\hline Methyl-thiophanate & LOQ & n.d. ${ }^{b}$ & $<\mathrm{LOQ}$ & n.d \\
\hline Dimetomorph & $1.427 \pm 0.003$ & $1.927 \pm 0.003$ & $1.625 \pm 0.006$ & $1.848 \pm 0.009$ \\
\hline Azoxystrobin & $<\mathrm{LOQ}$ & $<$ LOQ & $<$ LOQ & $<\mathrm{LOQ}$ \\
\hline Tebuconazole & $<$ LOQ & $<\mathrm{LOQ}$ & $<\mathrm{LOQ}$ & $<\mathrm{LOQ}$ \\
\hline
\end{tabular}

a Results are given as the average of three replicate assays $\pm \mathrm{SD}$.

b n.d.: not detected.

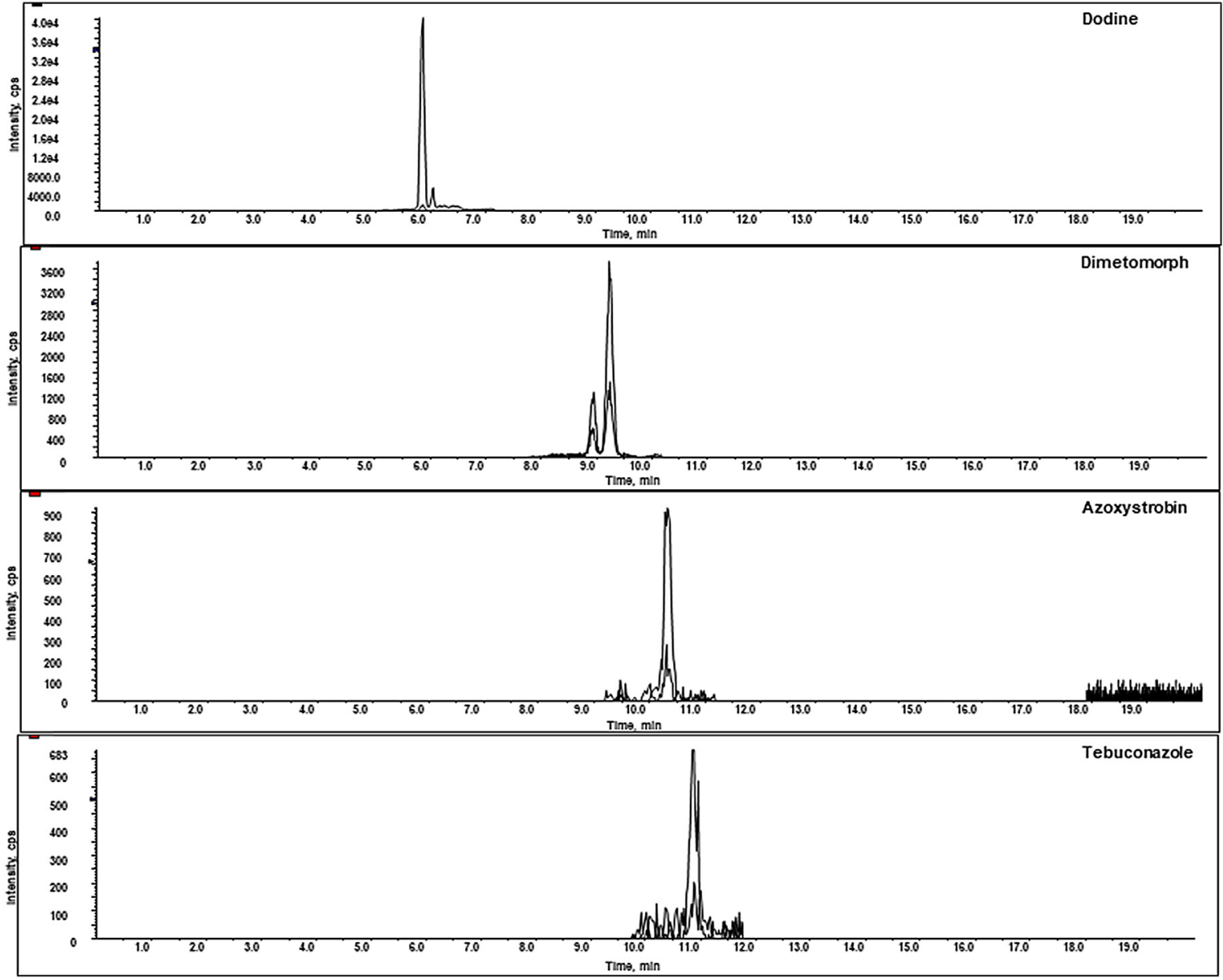

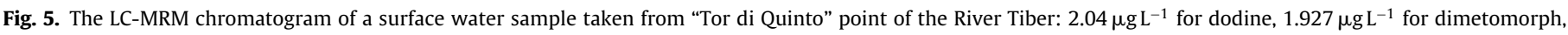
$\sim$ LOQ for azoxystrobin and tebuconazole.

of $\left.\mathrm{ChCl}(\mathrm{ASA})_{2} \mathrm{MeOH}\right)$ ) and rescaling the volumes proportionately $\left(2 \mathrm{~mL}\right.$ of THF and $200 \mu \mathrm{L}$ of $\left.\mathrm{ChCl}(\mathrm{ASA})_{2} \mathrm{MeOH}\right)$ ). For this reason, the $5-\mathrm{mL}$ volume was identified as the best solution and was utilized to conduct the study of validation and feasibility on real samples.

\subsection{Analytical method validation}

Recovery, precision, linearity, sensitivity, limit of detection (LOD), and limit of quantification (LOQ) were evaluated spiking preextraction blank samples with the analytes. All the related results are listed in Tables 3 and 4.

\subsubsection{Matrix-matched calibration curves, LODs and LOQs}

Calibration curves were constructed spiking seven $5-\mathrm{mL}$ aliquots of surface water with increasing concentrations of the analytes $\left(0.03,1,10,20,30,40,50 \mu \mathrm{g} \mathrm{L}^{-1}\right)$. Extraction and analysis were carried out according to what described in the Experimen- tal Section. Peak areas were plotted versus spike level by applying the least-square method $(\mathrm{y}=\mathrm{mx}+\mathrm{q}$ as regression model $)$. All the determination coefficients $\left(R^{2}\right)$ were above 0.97 (Table 3 ).

LODs and LOQs were assessed as the spike level detectable and quantifiable with a signal-to-noise ratio of 3 and 10, respectively (six replicates). To this end, blank real samples were fortified preextraction with the analytes at decreasing concentrations until to meet the described requirements. LODs spanned from $0.002 \mu \mathrm{g} \mathrm{L}^{-1}$ (azoxystrobin) to $2.3 \mu \mathrm{g} \mathrm{L}^{-1}$ (fludioxonil), depending on extraction efficiency and ES-MS sensitivity (see Table 3 for all data).

\subsubsection{Recovery and precision}

To calculate recovery and intra-day precision, five aliquots $(5 \mathrm{~mL})$ of natural water were spiked pre-extraction with the pesticides at two concentration levels corresponding to LOQ and 10 LOQ; another aliquot was spiked post-extraction with the same nominal concentrations of the analytes. All of these aliquots were 
Table 6

Comparison of the main merit figures of some recent methods.

\begin{tabular}{|c|c|c|c|c|c|c|}
\hline Method & Common analytes & $\begin{array}{l}\text { Recovery(spike } \\
\text { level }) \%\left(\mu \mathrm{g} \mathrm{L}^{-1}\right)\end{array}$ & $\begin{array}{l}\text { Repeteability(spike } \\
\text { level }) \%\left(\mu \mathrm{g} \mathrm{L}^{-1}\right)\end{array}$ & $\begin{array}{l}\text { Time per } \\
\text { sample(min) }\end{array}$ & $\operatorname{LOQ}\left(\mu \mathrm{g} \mathrm{L}^{-1}\right)$ & Reference \\
\hline $\begin{array}{l}\text { DLLME-SFO }{ }^{\mathrm{a}} \text {-LC- } \\
\text { MS/MS(extraction solvent: } \\
\text { 1-dodecanol) }\end{array}$ & azoxystrobin, propiconazole, tebuconazole & $100-103(0.1-0.5)$ & $2-12(0.1-0.5)$ & $\sim 20$ & $0.1-0.5$ & [39] \\
\hline $\begin{array}{l}\text { SD-DLLME }{ }^{\mathrm{b}} \text {-LC- } \\
\text { MS/MS(extraction solvent: } \\
\text { octanol) }\end{array}$ & $\begin{array}{l}\text { azoxystrobin, propiconazole, } \\
\text { pyraclostrobin, tebuconazole, }\end{array}$ & $\begin{array}{l}80-114(0.0125- \\
0.125)\end{array}$ & $2-25(0.0125-0.125)$ & $\sim 15$ & $0.0125-0.125$ & {$[40]$} \\
\hline $\begin{array}{l}\text { IL-DLLME }{ }^{\mathrm{C}}-\text { HPLC- } \\
\text { DAD(extraction solvent: } \\
\left.\left[\mathrm{C}_{6} \mathrm{MIM}\right]\left[\mathrm{PF}_{6}\right]\right)\end{array}$ & buprofezin, and hexythiazox & $98-110(5)$ & $9-10(5)$ & $\sim 15$ & $5-13$ & [41] \\
\hline SBSE-LD ${ }^{\mathrm{d}}$-LC-MSMS & $\begin{array}{l}\text { azoxystrobin, chlorpyrifos, dimethomorph, } \\
\text { tebuconazole }\end{array}$ & $99-101(0.02-0.1)$ & $8-11(0.02-0.1)$ & $>60$ & $0.02-0.1$ & {$[42]$} \\
\hline $\begin{array}{l}\text { SPE-HPLC- } \\
\text { Q/Orbitrap(sorbent:OASIS- } \\
\text { HLB) }\end{array}$ & $\begin{array}{l}\text { acetamiprid, azoxystrobin, boscalid, } \\
\text { buprofezin, chlorpyrifos-ethyl, } \\
\text { dimethomorph, fluquinconazole, } \\
\text { hexythiazox, imidacloprid, } \\
\text { methoxyfenozide, penconazole, } \\
\text { propiconazole, pyraclostrobin, } \\
\text { spirotetramat, tebuconazole, tebufenpyrad }\end{array}$ & $35-105(0.01-0.05)$ & $1-14(0.01-0.05)$ & $>60$ & $0.0005-0.01$ & [43] \\
\hline $\begin{array}{l}\text { SUPRAS-LPME-HPLC-UV } \\
\text { (SUPRAS: Decanoic } \\
\text { acid + tetrabutyl } \\
\text { ammonium hydroxide } \\
(3.9 \mathrm{~g})\end{array}$ & chlorpyrifos & $94-107(40-80)$ & $4.1-5.3(100-200)$ & $\sim 15$ & $1.2^{\mathrm{e}}$ & {$[45]$} \\
\hline $\begin{array}{l}\text { LTTM-DLLME-LC- } \\
\text { MS/MS(extraction solvent: } \\
\left.\text { ChCl(ASA })_{2}\right)\end{array}$ & $\begin{array}{l}\text { acetamiprid, azoxystrobin, boscalid, } \\
\text { buprofezin, chlorpyrifos-ethyl, } \\
\text { dimethomorph, fluquinconazole, } \\
\text { hexythiazox, imidacloprid, } \\
\text { methoxyfenozide, penconazole, } \\
\text { propiconazole, pyraclostrobin, } \\
\text { spirotetramat, tebuconazole, tebufenpyrad }\end{array}$ & $18-94(0.006-0.1)$ & $3-14(0.006-0.1)$ & $\sim 15$ & $(0.006-0.1)$ & This work \\
\hline $\begin{array}{l}\text { a DLLME based on solidificati } \\
\text { b Solvent-based de-emulsific } \\
\text { c Ionic liquid DLLME. } \\
\text { d Stir bar sorptive extraction- } \\
\text { e This value was calculated c }\end{array}$ & $\begin{array}{l}\text { of floating organic droplets (DLLME-SFO). } \\
\text { on DLLME (SD-DLLME). } \\
\text { quid desorption. } \\
\text { sidering the LOD }=0.35 \mu \mathrm{g} \mathrm{L}^{-1}(\mathrm{~S} / \mathrm{N}=3) \text {. }\end{array}$ & & & & & \\
\hline
\end{tabular}

analyzed in the same analytical session, while other two additional analytical sessions were performed to evaluate inter-day precision. In all cases, relative standard deviation (RSD), expression of the method precision, was $\leq 15 \%$ (see Table 4 ). The use of the 24 model compounds, characterized by different physicochemical properties (Table S1), allowed us to verify that $\mathrm{ChCl}(\mathrm{ASA})_{2}$ is effective in extracting neutral compounds with $\log P$ greater than 2 and much and much less with very polar compounds (see imidacloprid and acetamiprid).

\subsection{Analysis of environmental water samples}

The method effectiveness was assessed by analyzing the water samples collected at four different points of the River Tiber in May 2018 and analyzed. The results, averaged in triplicate, are summarized in Table 5. The most frequently detected substances in the sampled waters were the dodine and dimetomorph fungicides; all of others were undetected or detected under LOQ and within the permitted limits when established (see Fig. 5). The distribution of pesticides was more or less uniform, since there was not a significant difference between rural and urban areas.

\subsection{Comparison with other extraction methods}

The main figures of merit (recovery, precision, LOQ and analysis time) of the procedure were compared with those of the previous methods developed to extract some common analytes from environmental water samples [39-44] (see Table 6). Excluding the method relying on HPLC-DAD [41], our procedure exhibits comparable or much lower LOQs (up to 17 times minor); obvious exception is the procedure involving SPE [43] since it is able to achieve a significantly higher EF than that permitted by any DLLME procedure. As far as recovery and precision are concerned, our method shows an analogue performance than the others [39-43; 45], with the difference that we evaluated these parameters applying lower spike levels (from 2 up to 17 times for all DLLME-based procedures [39-42]). Regarding extraction time, our procedure is as rapid as the other ones relying on the same technique [39-41], but it is more sensitive, safer for the operator, and more eco-compatible for the environment due to the use of this specific neoteric solvent.

Another class of neoteric solvents worth of being mentioned and compared with LTTMs is that of supramolecular solvents (SUPRASs) [44]. SUPRASs are nanostructured liquids, composed of threedimensional amphiphilic aggregates, which are water-immiscible. Like LTTMs, their singular physicochemical properties make them other attractive alternatives to the organic solvents in LPME [45]. In the only method we found [45], the recovery yield of chlorpyrifos is high, but also in this case the spike level is from 11 up to 57 times higher.

\section{Conclusions}

In this paper, a novel LTTM was prepared and characterized for the first time in our laboratory. Our study has evidenced the amorphous nature of $\mathrm{ChCl}(\mathrm{ASA})_{2}$ and has proved that no changes occur when a small volume of $\mathrm{MeOH}$ is added $\left(\mathrm{ChCl}(\mathrm{ASA})_{2}: \mathrm{MeOH}\right.$ $1: 1.8 \mathrm{M}$ ratio) to reduce its viscosity. When $\mathrm{ChCl}(\mathrm{ASA})_{2}$ was tested as extracting phase to perform DLLME, the developed procedure showed the typical advantages of the micro-extraction technique combined with those inherent in the use of a neoteric solvent. Like any other DES/LTTM/IL, $\mathrm{ChCl}(\mathrm{ASA})_{2}$ has negligible vapor pressure, resulting an eco-compatible and safe solvent. This property also 
makes the use of LTTM analytically convenient since the analyte concentration in the final extract cannot be altered for solvent evaporation. On the other hand, such an event is probable when DLLME is carried out with a chlorinated solvent, whose use furthermore obliges to an evaporation step because of its limited compatibility with a reversed mobile phase. Although evaporation of a chlorinated solvent is a fast step, the LTTM can be simply diluted with $\mathrm{MeOH}$ to increase its polarity and to be directly analyzed. Finally, this study has highlighted that ideal candidates for extractions carried out with $\mathrm{ChCl}(\mathrm{ASA})_{2}$ are neutral compounds with $\log \mathrm{P}$ greater than 2 , while very polar compounds are poorly recovered.

\section{Funding}

The authors thank "Sapienza University" for having funded the research starting up project (protocol number AR118164361EF599).

\section{Appendix A. Supplementary data}

Supplementary material related to this article can be found, in the online version, at doi:https://doi.org/10.1016/j.chroma.2019. 06.050 .

\section{References}

[1] E.L. Smith, A.P. Abbott, K.S. Ryder, Deep eutectic solvents (DESs) and their applications, Chem. Rev. 114 (2014) 11060-11082, http://dx.doi.org/10.1021/ cr300162p.

[2] M. Francisco, A. van den Bruinhorst, M.C. Kroon, Low-transition-temperature mixtures (LTTMs): a new generation of designer solvents, Angew. Chem. Int Ed. Engl. 52 (2013) 3074-3085, http://dx.doi.org/10.1002/anie.201207548.

[3] E. Perales, C.B. García, L. Lomba, L. Aldea, J.I. García, B. Giner, Comparative ecotoxicology study of two neoteric solvents: imidazolium ionic liquid vs. glycerol derivative, Ecotoxicol. Environ. Saf. 132 (2016) 429-434, http://dx. doi.org/10.1016/j.ecoenv.2016.05.021.

[4] L.I. Tomé, V. Baião, W. da Silva, C.M. Brett, Deep eutectic solvents for the production and application of new materials, Appl. Mater. Today 10 (2018) 30-50, http://dx.doi.org/10.1016/j.apmt.2017.11.005.

[5] A.P. Abbott, G. Capper, D.L. Davies, R.K. Rasheed, V. Tambyrajah, Novel solvent properties of choline chloride/urea mixtures, Chem. Commun. 1 (2003) 70-71, http://dx.doi.org/10.1039/B210714G.

[6] H.A. Laitinen, W.S. Ferguson, R.A. Osteryoung, Preparation of pure fused Lithium chloride-potassium chloride eutectic solvent, J. Electrochem. Soc. 104 (1957) 516-520, http://dx.doi.org/10.1149/1.2428639.

[7] F.R. Duke, M.L. Iverson, Complex ions in fused salts, J. Phys. Chem. 62 (1958) 417-418, http://dx.doi.org/10.1021/j150562a009.

[8] M. Gambino, P. Gaune, M. Nabavian, M. Gaune-Escard, J.P. Bros, Enthalpie de fusion de l'uree et de quelques mélanges eutectiques a base d'uree, Thermochim. Acta 11 (1987) 37-47, http://dx.doi.org/10.1016/00406031(87)88032-2.

[9] C.R. Ashworth, R.P. Matthews, T. Welton, P.A. Hunt, Doubly ionic hydrogen bond interactions within the choline chloride-urea deep eutectic solvent, Phys. Chem. Chem. Phys. 18 (2016) 18145-18160, http://dx.doi.org/10.1039/ C6CP02815B.

[10] A.P. Abbott, G. Capper, D.L. Davies, H.L. Munro, R.K. Rasheed, V. Tambyrajah, Preparation of novel, moisture-stable, Lewis-acidic ionic liquids containing quaternary ammonium salts with functional side chains, Chem. Commun. 19 (2001) 2010-2011, http://dx.doi.org/10.1039/B106357J.

[11] M. Francisco, A. van den Bruinhorst, M.C. Kroon, New natural and renewable low transition temperature mixtures (LTTMs): screening as solvents for lignocellulosic biomass processing, Green Chem. 14 (2012) 2153-2157. http://dx.doi.org/10.1039/C2GC35660K.

[12] P. Gilli, L. Pretto, V. Bertolasi, G. Gilli, Predicting hydrogen-bond strengths from acid-base molecular properties. The pKa slide rule: toward the solution of a long-lasting problem, Acc. Chem. Res. 42 (2008) 33-44, http://dx.doi.org/ 10.1021/ar800001k.

[13] E. Durand, J. Lecomte, P. Villeneuve, From green chemistry to nature: the versatile role of low transition temperature mixtures, Biochimie 120 (2016) 119-123, http://dx.doi.org/10.1016/j.biochi.2015.09.019.

[14] S.C. Cunha, J. Fernandes, Extraction techniques with deep eutectic solvents, Trends Anal. Chem. 105 (2018) 225-239, http://dx.doi.org/10.1016/j.trac 2018.05.001.

[15] T. Khezeli, A. Daneshfar, R. Sahraei, Emulsification liquid-liquid microextraction based on deep eutectic solvent: an extraction method for the determination of benzene, toluene, ethylbenzene and seven polycyclic aromatic hydrocarbons from water samples, J. Chromatogr. A 1425 (2015) 25-33, http://dx.doi.org/10.1016/j.chroma.2015.11.007, 1425.
[16] T. Khezeli, A. Daneshfar, R. Sahraei, A green ultrasonic-assisted liquid-liquid microextraction based on deep eutectic solvent for the HPLC-UV determination of ferulic, caffeic and cinnamic acid from olive, almond, sesame and cinnamon oil, Talanta 150 (2016) 577-585, http://dx.doi.org/10.1016/j. talanta.2015.12.077.

[17] M.A. Farajzadeh, M.R.A. Mogaddam, M. Aghanassab, M. Deep eutectic solvent-based dispersive liquid-liquid microextraction, Anal. Methods 8 (2016) 2576-2583, http://dx.doi.org/10.1039/C5AY03189C.

[18] M.A. Farajzadeh, M. Sattari Dabbagh, A. Yadeghari, Deep eutectic solvent based gas-assisted dispersive liquid-phase microextraction combined with gas chromatography and flame ionization detection for the determination of some pesticide residues in fruit and vegetable samples, J. Sep. Sci. 40 (2017) 2253-2260, http://dx.doi.org/10.1002/jssc.201700052.

[19] H. Wang, L. Hu, X. Liu, S. Yin, R. Lu, S. Zhang, W. Zhou, H. Gao, Deep eutectic solvent-based ultrasound-assisted dispersive liquid-liquid microextraction coupled with high-performance liquid chromatography for the determination of ultraviolet filters in water samples, J. Chromatogr. A 1516 (2017) 1-8, http://dx.doi.org/10.1016/j.chroma.2017.07.073.

[20] N. Lamei, M. Ezoddin, K. Abdi, Air assisted emulsification liquid-liquid microextraction based on deep eutectic solvent for preconcentration of methadone in water and biological samples, Talanta 165 (2017) 176-181, http://dx.doi.org/10.1016/j.talanta.2016.11.036.

[21] S.M. Yousefi, F. Shemirani, S.A. Ghorbanian, Deep eutectic solvent magnetic bucky gels in developing dispersive solid phase extraction: application for ultra trace analysis of organochlorine pesticides by GC-micro ECD using a large-volume injection technique, Talanta 168 (2017) 73-81, http://dx.doi. org/10.1016/j.talanta.2017.03.020.

[22] F. Aydin, E. Yilmaz, M. Soylak, A simple and novel deep eutectic solvent based ultrasound-assisted emulsification liquid phase microextraction method for malachite green in farmed and ornamental aquarium fish water samples, Microchem. J. 132 (2017) 280-285, http://dx.doi.org/10.1016/j.microc.2017. 02.014 .

[23] H. Zeng, K. Qiao, X. Li, M. Yang, S. Zhang, R. Lu, J. Li, H. Gao, W. Zhou, Dispersive liquid-liquid microextraction based on the solidification of deep eutectic solvent for the determination of benzoylureas in environmental water samples, J. Sep. Sci. 40 (2017) 4563-4570, http://dx.doi.org/10.1002/ jssc.201700890.

[24] V. Ferrone, S. Genovese, M. Carlucci, M. Tiecco, R. Germani, F. Preziuso, F. Epifano, G. Carlucci, V.A. Taddeo, A green deep eutectic solvent dispersive liquid-liquid micro-extraction (DES-DLLME) for the UHPLC-PDA determination of oxyprenylated phenylpropanoids in olive, soy, peanuts, corn, and sunflower oil, Food Chem. 245 (2018) 578-585, http://dx.doi.org/ 10.1016/j.foodchem.2017.10.135.

[25] M. Rezaee, Y. Assadi, M.R.M. Hosseini, E. Aghaee, F. Ahmadi, S. Berijani, Determination of organic compounds in water using dispersive liquid-liquid microextraction, J. Chromatogr. A 1116 (2006) 1-9, http://dx.doi.org/10.1016 j.chroma.2006.03.007.

[26] G. Johansson, M. Sandström, Computer programs for the analysis of data on X-ray diffraction by liquids, Chem. Scr. 4 (1973) 195-198.

[27] C.M.V. Stålhandske, I. Persson, M. Sandström, E. Kamienska-Piotrowicz, A large angle scattering and vibrational spectroscopic study of the solvated zinc cadmium and mercury(II) ions in $\mathrm{N}, \mathrm{N}$-dimethylthioformamide solution, Inorg. Chem. 36 (1997) 3174-3182.

[28] International Tables for X-Ray Crystallography, Vol. 4, Kynoch Press, Birmingham, U.K, 1974

[29] D.T. Cromer, Compton scattering factors for aspherical free atoms, J. Chem. Phys. 50 (1969) 4857-4859, http://dx.doi.org/10.1063/1.1670980.

[30] D.T. Cromer, J.B. Mann, Compton scattering factors for spherically symmetric free atoms, J. Chem. Phys. 47 (1967) 1892-1894, http://dx.doi.org/10.1063/1. 1712213.

[31] M. Molund, I. Persson, STEPLR - a program for refinements of data on X-ray scattering by liquids, Chem. Scr. 25 (1985), 197-197.

[32] H.A. Levy, M.D. Danford, A.H. Narten, Data Collection and Evaluation With an X-Ray Diffractometer Designed for the Study of Liquid Structure, Technical Report ORNL-3960, Oak Ridge National Laboratory, Oak Ridge, TN, 1966.

[33] I.M. Aroso, J.C. Silva, F. Mano, A.S.D. Ferreira, M. Dionísio, I. Sá-Nogueira, S. Barreiros, R.L. Reis, A. Paiva, A.R.C. Duarte, Dissolution enhancement of active pharmaceutical ingredients by therapeutic deep eutectic systems, Eur. J. Pharm. Biopharm. 98 (2016) 57-66, http://dx.doi.org/10.1016/j.ejpb.2015.11. 002.

[34] R. Craveiro, I. Aroso, V. Flammia, T. Carvalho, M.T. Viciosa, M. Dionísio, S. Barreiros, R.L. Reis, A.R.C. Duarte, A. Paiva, Properties and thermal behavior of natural deep eutectic solvents, J. Mol. Liq. 215 (2016) 534-540, http://dx.doi. org/10.1016/j.molliq.2016.01.038.

[35] F. Chemat, H. Anjum, A.M. Shariff, P. Kumar, T. Murugesan, Thermal and physical properties of (Choline chloride+ urea+ l-arginine) deep eutectic solvents, J. Mol. Liq. 218 (2016) 301-308, http://dx.doi.org/10.1016/j.molliq. 2016.02.062.

[36] Y.A. Ribeiro, A.C.F. Caires, N. Boralle, M. Ionashiro, Thermal decomposition of acetylsalicylic acid (aspirin), Thermochim. Acta 279 (1996) 177-181, http:// dx.doi.org/10.1016/0040-6031(96)90082-9.

[37] J.C. Reepmeyer, Thermal decomposition of aspirin: formation of linear oligomeric salicylate esters, J. Pharm. Sci. 72 (1983) 322-323.

[38] S.L. Perkins, P. Painter, C.M. Colina, Molecular dynamic simulations and vibrational analysis of an ionic liquid analogue, J. Phys. Chem. B 117 (2013) 10250-10260, http://dx.doi.org/10.1021/jp404619x. 
[39] L.C. Marube, S.S. Caldas, K.L. Soares, E.G. Primel, Dispersive liquid-liquid microextraction with solidification of floating organic droplets for simultaneous extraction of pesticides, pharmaceuticals and personal care products, Microchim. Acta 182 (2015) 1765-1774, http://dx.doi.org/10.1007/ s00604-015-1507-7.

[40] S.S. Caldas, C. Rombaldi, J.L. de Oliveira Arias, L.C. Marube, E.G. Primel, Multi-residue method for determination of 58 pesticides, pharmaceuticals and personal care products in water using solvent demulsification dispersive liquid-liquid microextraction combined with liquid chromatography-tandem mass spectrometry, Talanta 146 (2016) 676-688, http://dx.doi.org/10.1016/j. talanta.2015.06.047.

[41] Y. Liu, E. Zhao, W. Zhu, H. Gao, Z. Zhou, Determination of four heterocyclic insecticides by ionic liquid dispersive liquid-liquid microextraction in water samples, J. Chromatogr. A 1216 (2009) 885-891, http://dx.doi.org/10.1016/j. chroma.2008.11.076

[42] C. Margoum, C. Guillemain, X. Yang, M. Coquery, Stir bar sorptive extraction coupled to liquid chromatography-tandem mass spectrometry for the determination of pesticides in water samples: method validation and measurement uncertainty, Talanta 116 (2013) 1-7, http://dx.doi.org/10.1016/ j.talanta.2013.04.066.

[43] J. Casado, D. Santillo, P. Johnston, Multi-residue analysis of pesticides in surface water by liquid chromatography quadrupole-Orbitrap high resolution tandem mass spectrometry, Anal. Chim. Acta 1024 (2018) 1-17, http://dx.doi org/10.1016/j.aca.2018.04.026.

[44] A. Ballesteros-Gómez, M.D. Sicilia, S. Rubio. Supramolecular solvents in the extraction of organic compounds. A review, Anal. Chim. Acta 677 (2010) 108-130, http://dx.doi.org/10.1016/j.aca.2010.07.027.

[45] P. Zohrabi, M. Shamsipur, M. Hashemi, B. Hashemi, Liquid-phase microextraction of organophosphorus pesticides using supramolecular solvent as a carrier for ferrofluid, Talanta 160 (2016) 340-346, http://dx.doi. org/10.1016/j.talanta.2016.07.036. 